\title{
THEORETICAL RESEARCH ON EFFECTS OF SUBSTITUENTS AND THE SOLVENT ON QUADRUPLE HYDROGEN BONDED COMPLEXES
}

\author{
Lingjia Xu, Yuqi Ding and Qiwen Teng*
}

\author{
Department of Chemistry, Zhejiang University, Hangzhou 310027, P.R. China
}

(Received August 29, 2006; revised February 26, 2007)

\begin{abstract}
Semiempirical AM1 and INDO/CIS methods were used to study the structures and spectroscopy of hydrogen bonded complexes formed by the oligophenyleneethynylene (monomer A) with isophthalic acid (monomer B). The binding energies of the complexes are lowered by increasing electron-donating abilities of the substituents near the hydrogen bonds on monomer A. The first absorptions in the electronic spectra and the vibration frequencies of the N-H bonds in the IR spectra for the complexes are both red-shifted compared with those of the monomers. The presence of dimethylsulfoxide (DMSO) can reduce the binding energy of the complex through hydrogen bonding. This results in a blue-shift for the first absorption in the electronic spectrum and redshift for the vibration frequencies of the N-H bonds in the IR spectrum of the complex.
\end{abstract}

KEY WORDS: Oligophenyleneethynylene, Hydrogen bonding, Solvent effect, Semiempirical methods

\section{INTRODUCTION}

Hydrogen bonding plays an important role in nature [1-5], especially in the biological materials and life processes related to DNA and drug design [6,7]. It is also significant in study on the different solvent environments in the living organism [8]. Thus hydrogen bonding is applied in many ways such as synthesis of polymers, self-assembly of functional materials, drug design and crystal engineering. Quadruple hydrogen bonds occur extensively in dimer of specific structures like dendronized dimers bearing oligoether dendrons and a dimeric 2-ureido-4pyrimidinone [1]. A strong quadruple hydrogen bonding complex based on the ureidosubstituted cytosine moiety has potential for the construction of superamolecular arrays. The hydrogen bonding of cytosine and guanidine modules can be explored to generate novel superamolecular architectures [2]. Furthermore, hydrogen bonding interactions are expected to be the strongest and most persistent of the intermolecular interactions in organic crystal engineering [3]. They are used as the principal means to control molecular self-assembly during crystallization. The strong directing capabilities of hydrogen bonds are utilized to organize individual molecules into supramolecular aggregates that have well-defined structures. These aggregates often have unique chemical and physical properties due to the collective behavior of these weakly bound molecules [4]. Meanwhile, hydrogen bonds are also employed as an effective path for the self-assembly [5] and molecular recognition just as in the complexes formed by vacomycin with small molecules. The mechanical properties of these complexes can be improved, which is very important in drug delivery and tissue engineering [6]. On the other hand, modulating the hydrogen-bonding strength with proper substituents on a hydrogen donor and acceptor can be a very useful strategy in drug design [7].

In addition, the polar solvent DMSO affects hydrogen bonds, significantly. DMSO combines with the donor monomer via hydrogen bonding, thus inhibits the interaction between the donor and acceptor monomers. DMSO is also widely used in NMR spectra as an aprotic and polar solvent. Its oxygen atoms are easily involved in strong hydrogen bonding interactions with the acidic protons of solute molecules. DMSO often withdraws the electron density from the hydrogen atoms through the hydrogen bonding; therefore, these protons signals are shifted downfield [8].

*Corresponding author. E-mail: wushi@zju.edu.cn 
Besides NMR spectra [2, 3, 8], UV and IR spectra can also be used to characterize the formation of hydrogen-bonding complexes. Unlike the quadruple donor-donor-acceptoracceptor (DDAA) hydrogen bonding in the complex [2], acceptor-donor-donor-acceptor (ADDA) quadruple hydrogen bonds are included in the complexes formed by the oligophenyleneethynylene derivative with isophthalic acid. The effects of polar solvents upon association constants of the above complexes have been studied experimentally [9]. But the effects of substituents on the monomers on the stabilities and spectroscopy of the complexes have not yet been reported. Following the experimental synthesis described by Bielawaski et al. [9], we have carried out calculations on a series of complexes of substituted oligophenyleneethynylene derivatives with isophthalic acid, in order to examine the influence of substituents on their stabilities. The electronic structures and spectroscopic regularities for the complexes are explored and predicted.

\section{EXPERIMENTAL}

The binding energy $\Delta \mathrm{E}$ of a complex is equal to the total energy of the complex minus the energies of the two monomers [7, 10-13]. Oligophenyleneethynylene (monomer A), isophthalic acid (monomer B) and complex 1 formed by them are optimized using the AM1 method [14]. Complexes 2-10 are designed through changing the substituents and their positions on the monomers (shown in Figure 1). Complexes 11-12 are formed by introducing one mole or two moles of DMSO near monomer B above complex 1. The binding energies of complexes 11 and 12 are defined as the total energy of the complexes minus the energies of the two monomers and DMSO existing independently. These complexes are also optimized with the AM1 method.

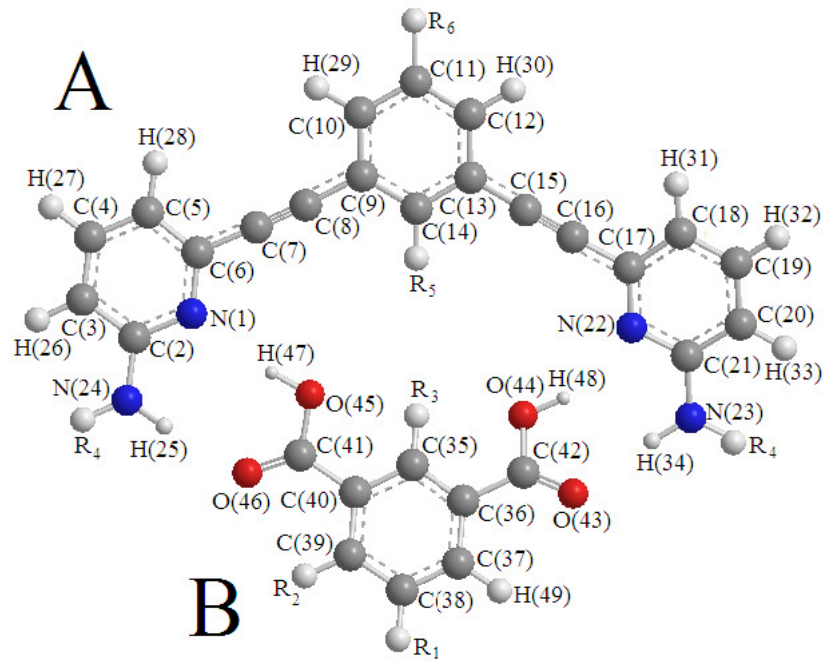

Complex 1: $\mathrm{R}_{1}=\mathrm{R}_{2}=\mathrm{R}_{3}=\mathrm{R}_{4}=\mathrm{R}_{5}=\mathrm{R}_{6}=\mathrm{H}$; complex 2: $\mathrm{R}_{1}=\mathrm{NH}_{2}, \mathrm{R}_{2}=\mathrm{R}_{3}=\mathrm{R}_{4}=\mathrm{R}_{5}=\mathrm{R}_{6}=$ $\mathrm{H}$; complex 3: $\mathrm{R}_{2}=\mathrm{NH}_{2}, \mathrm{R}_{1}=\mathrm{R}_{3}=\mathrm{R}_{4}=\mathrm{R}_{5}=\mathrm{R}_{6}=\mathrm{H}$; complex 4: $\mathrm{R}_{3}=\mathrm{NH}_{2}, \mathrm{R}_{1}=\mathrm{R}_{2}=\mathrm{R}_{4}=\mathrm{R}_{5}$ $=\mathrm{R}_{6}=\mathrm{H}$; complex 5: $\mathrm{R}_{4}=\mathrm{NH}_{2}, \mathrm{R}_{1}=\mathrm{R}_{2}=\mathrm{R}_{3}=\mathrm{R}_{5}=\mathrm{R}_{6}=\mathrm{H}$; complex 6: $\mathrm{R}_{4}=\mathrm{NHCH}_{3}, \mathrm{R}_{1}=\mathrm{R}_{2}$ $=\mathrm{R}_{3}=\mathrm{R}_{5}=\mathrm{R}_{6}=\mathrm{H}$; complex 7: $\mathrm{R}_{4}=\mathrm{NHCH}_{2} \mathrm{CH}_{3}, \mathrm{R}_{1}=\mathrm{R}_{2}=\mathrm{R}_{3}=\mathrm{R}_{5}=\mathrm{R}_{6}=\mathrm{H}$; complex 8: $\mathrm{R}_{4}=$ $\mathrm{NHCH}_{2} \mathrm{CH}_{2} \mathrm{CH}_{3}, \mathrm{R}_{1}=\mathrm{R}_{2}=\mathrm{R}_{3}=\mathrm{R}_{5}=\mathrm{R}_{6}=\mathrm{H}$; complex 9: $\mathrm{R}_{4}=\mathrm{NHCH}_{2} \mathrm{CH}_{2} \mathrm{CH}_{2} \mathrm{CH}_{3}, \mathrm{R}_{1}=\mathrm{R}_{2}=$ $\mathrm{R}_{3}=\mathrm{R}_{5}=\mathrm{R}_{6}=\mathrm{H}$; complex 10: $\mathrm{R}_{4}=\mathrm{NHC}\left(\mathrm{CH}_{3}\right)_{3}, \mathrm{R}_{1}=\mathrm{R}_{2}=\mathrm{R}_{3}=\mathrm{R}_{5}=\mathrm{R}_{6}=\mathrm{H}$.

Figure 1 . The scheme of the hydrogen-bonding complexes 1-10 studied in the passage. 
Based on the AM1 optimized geometries, the electronic spectra of the complexes are computed employing the INDO/CIS method as in the ZINDO program without any adjustment of the parameters [15-17]. One hundred and ninety-seven configurations including the ground state are generated by exciting electrons from the 14 highest occupied molecular orbits (HOMO) into the 14 lowest unoccupied molecular orbits (LUMO). Finally, the IR frequencies and intensities of the complexes are calculated utilizing the AM1 method in GAUSSIAN 03 program [18].

\section{RESULTS AND DISCUSSION}

\section{The configurations and stabilities}

The binding energies for the complexes are presented in Table 1. The binding energy of complex 1 is $34.96 \mathrm{~kJ} \cdot \mathrm{mol}^{-1}$, compatible with the experimental binding energy $-29 \mathrm{~kJ} \cdot \mathrm{mol}^{-1}$ of the complex formed by methanol and water [19]. The calculated binding energy of a single hydrogen bond on the average in complex 1 is $8.74 \mathrm{~kJ} \cdot \mathrm{mol}^{-1}$, which is identical to $8.90 \mathrm{~kJ} \cdot \mathrm{mol}^{-1}$ of the complex formed by the amide and furan acceptor calculated at the B3LYP/6-31G ${ }^{* *}$ level [7]. In complexes 2,3 and 4 , the group $-\mathrm{NH}_{2}$ is added to the different locations on monomer $\mathrm{B}$. The presence of $-\mathrm{NH}_{2}$ results in the complicated chemical environment of $\mathrm{H}(47)$ and $\mathrm{O}(46)$, $\mathrm{H}(48)$ and $\mathrm{O}(43)$ on monomer B. The increase of electron density on these atoms cannot be simply described using the effect of the ortho-, meta- and para-positions. Monomer B is not only the proton donor, but also the proton acceptor; therefore, the binding energies of complexes 2, 3 and 4 are resulted from the comprehensive effect of the quadruple hydrogen bonding.

The binding energies of complexes 5-9 are decreased gradually. The electron density on $\mathrm{N}(23)$ or $\mathrm{N}(24)$ on monomer $\mathrm{A}$ is enhanced since the substituents $\mathrm{R}_{4}$ possess the increasing electron-donating abilities. Then the $\mathrm{N}(23)-\mathrm{H}(34)$ and $\mathrm{N}(24)-\mathrm{H}(25)$ bonds are intensified, and the hydrogen bonds $\mathrm{H}(25) \ldots \mathrm{O}(46)$ and $\mathrm{H}(34) \ldots \mathrm{O}(43)$ are weakened. Therefore the increasing electron-donating abilities of the substituents $\mathrm{R}_{4}$ reduce stabilities of the complexes. Although the steric effects of the substituents $R_{4}$ become large, the electron-donating effects still play important role in the stabilities of the complexes. This is supported by the experimental result that the steric size of the dendrons does not exhibit a significant effect on their dimerization behavior of pyrimidinone [1]. On the contrary, the binding energy of complex 10 is the biggest, which is aroused by the large steric effect of $-\mathrm{C}\left(\mathrm{CH}_{3}\right)_{3}$. The experiment also shows that the dimerization of pyrimidinone is not hindered by the largest dendron located at $\mathrm{R}_{4}$ position, and the binding constant of the dimer bearing the group $-\mathrm{C}\left(\mathrm{CH}_{3}\right)_{3}$ is $6 \times 10^{7} \mathrm{M}^{-1}$, bigger than the others [1].

Table 1. The binding energies $(\Delta \mathrm{E})$ of complexes $1-12$.

\begin{tabular}{|l|c|c|c|c|c|c|}
\hline Complexes & 1 & 2 & 3 & 4 & 5 & 6 \\
\hline$\Delta \mathrm{E}\left(\mathrm{kJ} \cdot \mathrm{mol}^{-1}\right)$ & -34.96 & -33.10 & -33.37 & -36.59 & -36.70 & -33.40 \\
\hline Complexes & 7 & 8 & 9 & 10 & 11 & 12 \\
\hline$\Delta \mathrm{E}\left(\mathrm{kJ} \cdot \mathrm{mol}^{-1}\right)$ & -32.96 & -32.60 & -31.71 & -40.19 & -31.92 & -47.55 \\
\hline
\end{tabular}

In complex 11, DMSO is parallel with the plane located by monomer B, just as in the complex formed by barbituric acid with DMSO [8]. The plane of monomer B becomes almost perpendicular to that of monomer A due to its geometric rotation driven by the hydrogen bonding between DMSO and monomer B, shown in Figure 2(a). The two hydrogen bonds $\mathrm{H}(48) \ldots \mathrm{N}(22)$ and $\mathrm{H}(47) \ldots \mathrm{N}(1)$ are broken, and only one new hydrogen bond $\mathrm{H}(47) \ldots \mathrm{O}(50)$ is formed. The binding energy of complex 11 is less than that of complex 1 because the number of the hydrogen bonds in complex 11 is decreased in the presence of one mole of DMSO. This is in 
agreement with the experimental result that the association constant of the complex formed by the oligophenyleneethynylene derivative with the isophthalic acid is reduced due to the presence of DMSO [9]. The binding energy of complex 12 is larger than that of complex 11. There are two new hydrogen bonds $\mathrm{H}(47) \ldots \mathrm{O}(50)$ and $\mathrm{H}(48) \ldots \mathrm{O}(60)$ between DMSO and monomer B in complex 12 (Figure 2b). The interaction between DMSO and monomer B is arisen from hydrogen bonding, which is similar to that reported in the reference [8]. Thus the presence of DMSO changes the relative position and reduces the hydrogen bonds between the two monomers.

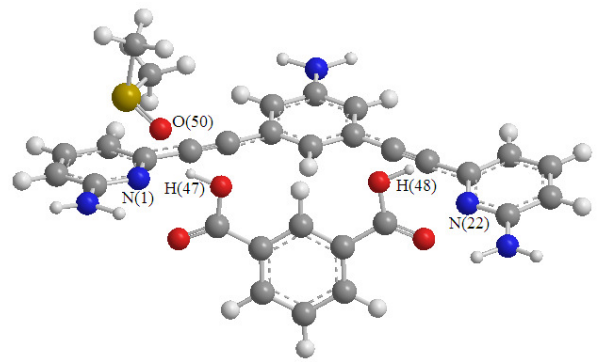

(a)

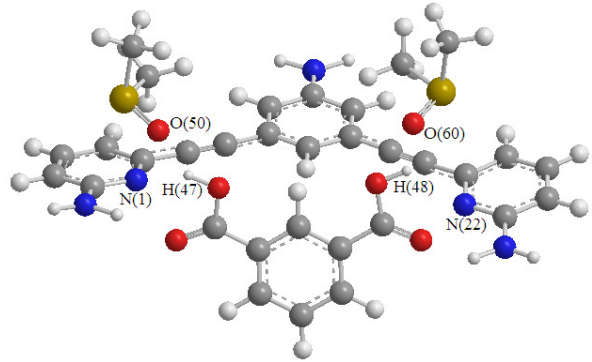

(b)

Figure 2. The optimized geometries of complexes 11(a) and 12(b).

\section{The electronic structures}

The HOMO and LUMO energies of complex 1 are -8.61 and $-0.77 \mathrm{eV}$, respectively. Its LUMOHOMO energy gap is $7.85 \mathrm{eV}$, less than those of monomers $\mathrm{A}$ and $\mathrm{B}$ (7.95 and $9.56 \mathrm{eV})$. The HOMO and LUMO energies of complex 5 are -8.09 and $-0.90 \mathrm{eV}$, and the energy gap is 7.19 $\mathrm{eV}$. The difference among the energy gaps of the other complexes is not very big according to the calculation, but these energy gaps are all less than those of the monomers (Figure 3). The properties of the frontier orbits in the complexes are changed due to the hydrogen bonding between monomers $\mathrm{A}$ and $\mathrm{B}$, which alters the energy gaps of the complexes. The energy gaps of complexes 11 and 12 (7.89 and $7.91 \mathrm{eV})$ are both larger than that of complex 1, indicating that the complexes are stabilized due to the presence of DMSO.

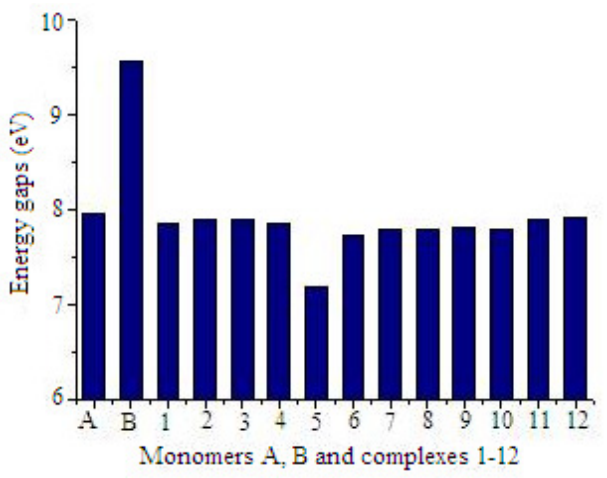

Figure 3. The energy gaps of monomers A, B and complexes 1-12. 
The dipole moment of complex 1 is $1.27 \times 10^{-30} \mathrm{~cm}$, less than those of complexes 6-10 $\left(4.39,4.03,3.67,3.73\right.$ and $\left.5.09 \times 10^{-30} \mathrm{~cm}\right)$. This is resulted from the presence of $-\mathrm{NR}_{2}$ in theses complexes and the separation of the centers between the positive and negative charges. The net charges of monomers A, B and DMSO in complex 11 are $-0.008,0.001$ and 0.006 , thus the electrons flow from monomer $\mathrm{B}$ to $\mathrm{A}$ at the presence of DMSO. The net charges of monomers $\mathrm{A}, \mathrm{B}$ and DMSO in complex 12 are $-0.008,-0.010$ and 0.017 , then the electrons are transferred from DMSO to monomers A and B. It is proved that DMSO behaves as an electron donator with the formation of the complexes. This is caused by the electron-donating abilities of the methyl groups and the deformability of the sulfur atom in DMSO.

\section{The electronic absorption spectra}

The strongest absorption at $299.1 \mathrm{~nm}$ of monomer A is compatible with the experiment [9]. The first absorption peak of complex 1 is computed at $317.8 \mathrm{~nm}$ (Figure 4). The first absorptions of complexes 4 and 10 appear at 322.4 and $318.7 \mathrm{~nm}$, respectively, which are red-shifted in comparison with that of complex 1 owing to their less energy gaps. Compared with complex 1 , complex 4 had more absorption peaks in the range of 213-271 nm. This broadening of the bands is a consequence of the formation of the hydrogen bonding and the decrease of the symmetry.
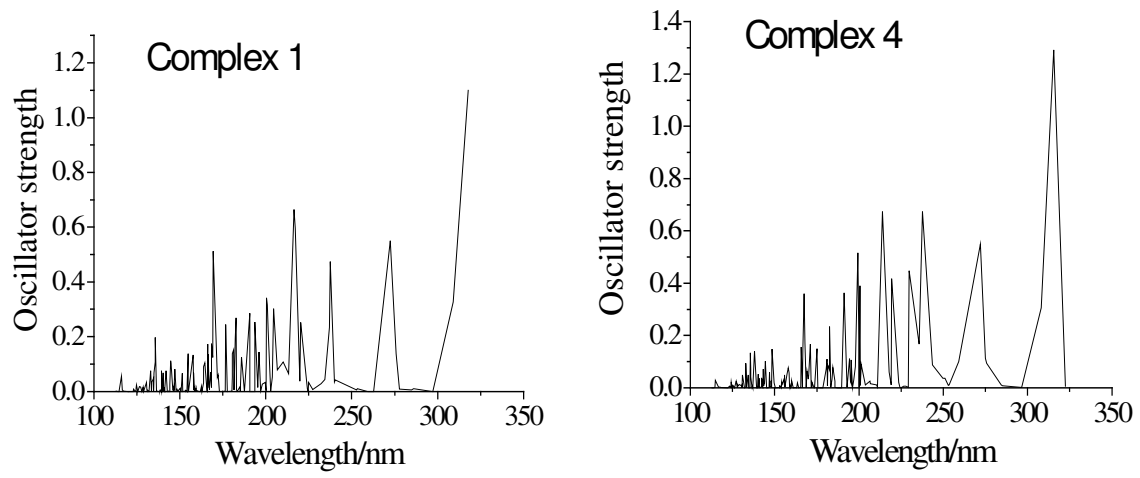

Figure 4. The electronic spectra of complexes 1 and 4.

The first absorptions (318.9, 318.6, 318.6, 318.5 and $318.9 \mathrm{~nm}$ ) of complexes 6-10 (Table 2) are little changed. The change from the atom $\mathrm{H}$ on $-\mathrm{NH}_{2}$ in monomer A to the methyl, ethyl, propyl, butyl and isobutyl groups, respectively, leads to the less impact on the first UV peaks of the complexes. The basic skeletons of the complexes are kept unchanged.

The first absorption of complex 2 is calculated at $316.5 \mathrm{~nm}$, which is mainly generated by the electronic transition from occupied orbital (91) to virtual orbital (95). The first absorption peaks at 316.5 and $314.5 \mathrm{~nm}$ of complexes 2 and 3 are blue-shifted, relative to that of complex 1, while the first peak at $346.8 \mathrm{~nm}$ of complex 5 are red-shifted. The first absorptions in the electronic spectra of the complexes are greatly affected by the substituting sites of the group $-\mathrm{NH}_{2}$ on monomer A.

The first band of complex 11 is computed to be at $312.2 \mathrm{~nm}$, which is blue-shifted compared with that of complex 1 . The decrease of the hydrogen bonds between monomers $\mathrm{A}$ and $\mathrm{B}$ in complex 11 at the presence of DMSO results in the less overlap of electron cloud. Thus the conjugated system becomes less. 
Table 2. The electronic spectra of complexes 2, 3, 5, 7, 8 and 9.

\begin{tabular}{|c|c|c|c|c|c|c|c|c|c|}
\hline Complex & $\lambda / \mathrm{nm}$ & $f$ & Trans. nature & Coeff. & Complex & $\lambda / \mathrm{nm}$ & $f$ & Trans. nature & Coeff. \\
\hline 2 & 316.5 & 0.996 & $(91) \rightarrow(95)$ & 0.609 & 7 & 318.6 & 1.090 & $(100) \rightarrow(104)$ & 0.612 \\
\hline & 309.8 & 0.209 & $(88) \rightarrow(92)$ & -0.868 & & 310.1 & 0.311 & $(100) \rightarrow(103)$ & 0.618 \\
\hline & 307.9 & 0.314 & $(91) \rightarrow(94)$ & -0.627 & & 285.9 & 0.003 & $(96) \rightarrow(103)$ & 0.691 \\
\hline & 296.3 & 0.001 & $(91) \rightarrow(95)$ & -0.461 & & 278.2 & 0.008 & $(93) \rightarrow(102)$ & -0.577 \\
\hline & 285.8 & 0.016 & $(86) \rightarrow(94)$ & 0.650 & & 275.2 & 0.178 & $(99) \rightarrow(105)$ & -0.436 \\
\hline & 284.5 & 0.012 & $(85) \rightarrow(94)$ & -0.599 & & 272.3 & 0.598 & $(100) \rightarrow(106)$ & 0.452 \\
\hline & 274.8 & 0.121 & $(91) \rightarrow(96)$ & -0.446 & & 253.7 & 0.012 & $(89) \rightarrow(104)$ & 0.507 \\
\hline & 272.2 & 0.554 & $(91) \rightarrow(97)$ & 0.453 & & 253.5 & 0.008 & $(90) \rightarrow(104)$ & -0.504 \\
\hline 3 & 314.5 & 0.425 & $(91) \rightarrow(95)$ & -0.405 & 8 & 318.6 & 1.073 & $(106) \rightarrow(110)$ & -0.606 \\
\hline & 314.1 & 0.186 & $(89) \rightarrow(92)$ & 0.320 & & 310.5 & 0.305 & $(106) \rightarrow(109)$ & 0.609 \\
\hline & 313.6 & 0.250 & $(89) \rightarrow(92)$ & -0.288 & & 297.5 & 0.001 & $(106) \rightarrow(110)$ & -0.446 \\
\hline & 312.1 & 0.368 & $(89) \rightarrow(92)$ & 0.558 & & 285.5 & 0.014 & $(102) \rightarrow(109)$ & -0.707 \\
\hline & 305.3 & 0.334 & $(91) \rightarrow(94)$ & -0.629 & & 284.3 & 0.005 & $(101) \rightarrow(109)$ & 0.658 \\
\hline & 295.3 & 0.003 & $(91) \rightarrow(95)$ & -0.484 & & 278.0 & 0.008 & $(98) \rightarrow(107)$ & 0.752 \\
\hline & 285.2 & 0.007 & $(86) \rightarrow(94)$ & -0.669 & & 274.8 & 0.136 & $(105) \rightarrow(111)$ & -0.460 \\
\hline & 283.7 & 0.013 & $(85) \rightarrow(94)$ & -0.565 & & 272.6 & 0.617 & $(106) \rightarrow(112)$ & -0.460 \\
\hline 5 & 346.8 & 0.857 & $(91) \rightarrow(94)$ & -0.872 & 9 & 318.9 & 1.084 & $(112 \rightarrow(116)$ & 0.610 \\
\hline & 314.2 & 0.235 & $(90) \rightarrow(94)$ & -0.604 & & 310.8 & 0.291 & $(112) \rightarrow(115)$ & 0.620 \\
\hline & 308.6 & 0.327 & $(90) \rightarrow(95)$ & -0.654 & & 297.4 & 0.002 & $(112) \rightarrow(116)$ & -0.447 \\
\hline & 286.2 & 0.011 & $(87) \rightarrow(94)$ & -0.525 & & 286.7 & 0.019 & $(108) \rightarrow(115)$ & 0.668 \\
\hline & 282.9 & 0.010 & $(86) \rightarrow(94)$ & -0.604 & & 285.0 & 0.009 & $(107) \rightarrow(115)$ & 0.633 \\
\hline & 281.0 & 0.020 & $(87) \rightarrow(94)$ & -0.468 & & 278.1 & 0.008 & $(104) \rightarrow(113)$ & 0.754 \\
\hline & 278.2 & 0.007 & $(83) \rightarrow(92)$ & 0.752 & & 274.9 & 0.022 & $(112) \rightarrow(115)$ & 0.500 \\
\hline & 274.9 & 0.605 & $(90) \rightarrow(97)$ & -0.508 & & 273.5 & 0.660 & $(112) \rightarrow(118)$ & 0.500 \\
\hline
\end{tabular}

\section{The IR spectra}

The first high-frequency absorption peak of complex 1 appears at $3333.9 \mathrm{~cm}^{-1}$, which is assigned as the stretching vibration of the N-H and O-H bonds. It is red-shifted relative to those of monomers A and B (3635.9 and $3417 \mathrm{~cm}^{-1}$ ), which is resulted from the formation of the hydrogen bonding in complex 1 and the weakening of the $\mathrm{N}-\mathrm{H}$ and $\mathrm{O}-\mathrm{H}$ bonds on monomers $\mathrm{A}$ and $\mathrm{B}$. This result is identical to the conclusion that the vibration frequencies of the $\mathrm{O}-\mathrm{H}$ bonds are reduced in the complex formed by methanol with $\mathrm{H}_{2} \mathrm{O}$ [20].

The first high-frequency absorptions of complexes 6 (Figure 5), 7, 8 and 9 occur at 3335.2, $3380.6,3388.3$ and $3342.9 \mathrm{~cm}^{-1}$, respectively. These frequencies are higher than that of complex 1. The electron densities on $\mathrm{N}(23)$ and $\mathrm{N}(24)$ are increased by the strong electron-donating groups $\mathrm{R}_{4}$ on monomer $\mathrm{A}$, thus the $\mathrm{N}(23)-\mathrm{H}(34)$ and $\mathrm{N}(24)-\mathrm{H}(25)$ bonds are strengthened.

The stretching vibration of the N-H and O-H bonds in complex 11 is $3327.5 \mathrm{~cm}^{-1}$, lower than that of complex 1. The relative movement between monomers $\mathrm{B}$ and $\mathrm{A}$ at the presence of DMSO leads to the shortening of the $\mathrm{H}(25) \ldots \mathrm{O}(46)$ bond from 0.218 to $0.215 \mathrm{~nm}$ and the lengthening of the $\mathrm{N}(24)-\mathrm{H}(25)$ bond. The lengths of the O...H hydrogen bonds in the daidzein derivatives are determined within 0.174-0.255 $\mathrm{nm}$ [5], which supports the above results. The formation of the two symmetrical hydrogen bonds between monomer B and DMSO in complex 12 results in the leaning of monomer $\mathrm{B}$ to the other side, which recovers the stretching vibration of the $\mathrm{N}(24)-\mathrm{H}(25)$ bond. Thus this $\mathrm{N}-\mathrm{H}$ vibration appears upfield $\left(3494.5 \mathrm{~cm}^{-1}\right)$. 

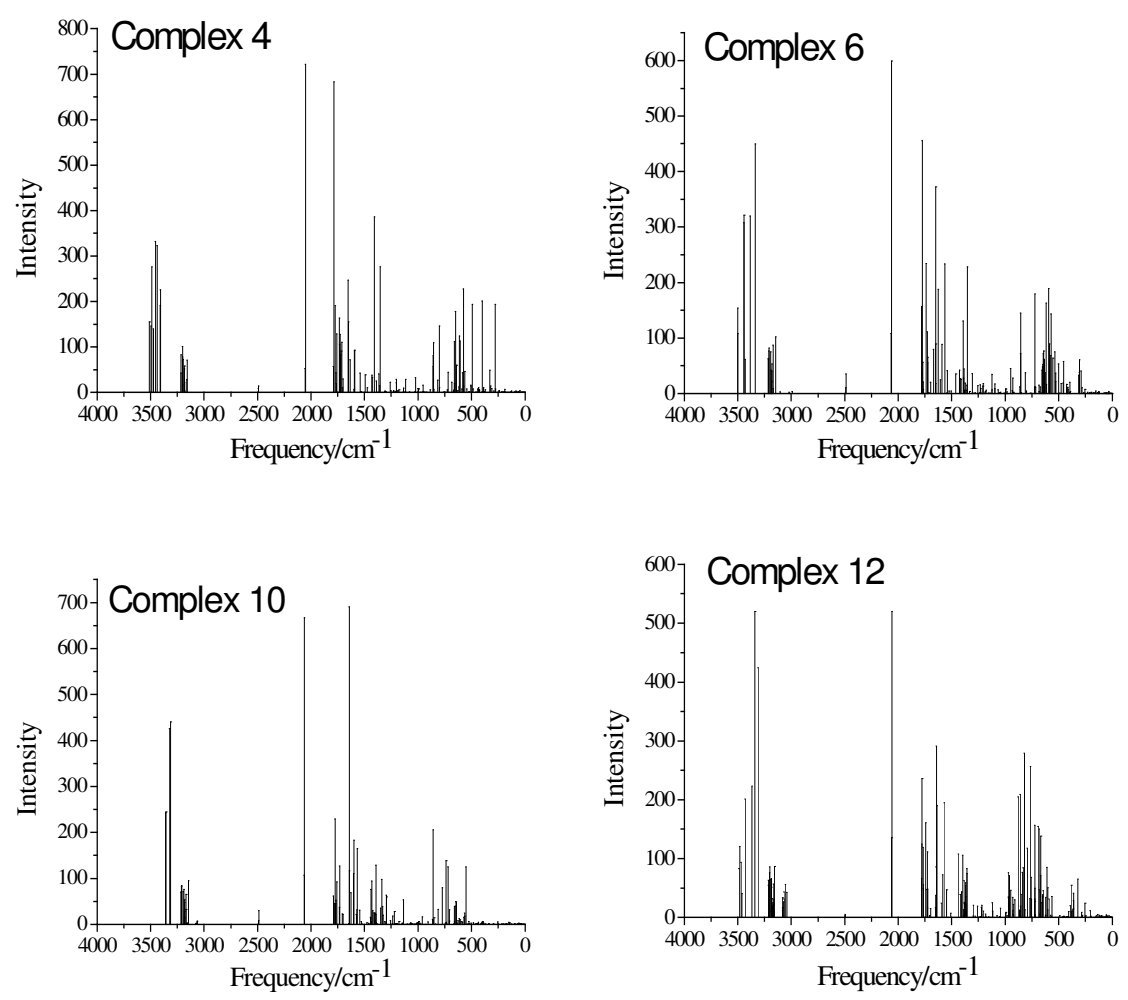

Figure 5. The IR spectra of complexes 4, 6, 10 and 12 .

\section{CONCLUSION}

The electron-donating substituents $\mathrm{R}_{4}$ of moderate size on monomer $\mathrm{A}$ are unfavorable to the stabilities of the complexes. The presence of DMSO results in the departure of monomer B from the original plane of monomer A. The LUMO-HOMO energy gaps of the complexes are less than those of the monomers, while the energy gap is increased due to the presence of DMSO. The electron-donating abilities of the methyl groups and the deformability of the sulfur atom in DMSO lead to the electron-donating character of DMSO in the complex. The first absorption in the electronic spectrum of the complex is blue-shifted in the presence of DMSO because the number of the hydrogen bonds in the complex is decreased and the conjugated system becomes less. The IR stretching vibrations of the N-H bonds on monomer A in the complex are weakened owing to the formation of the hydrogen bonding between DMSO and monomer B.

\section{REFERENCES}

1. Wong, C.H.; Chow, H.F.; Hui, S.K.; Sze, K.H. Org. Lett. 2006, 8, 1811.

2. Lafitte, V.G.H.; Aliev, A.E.; Horton, P.N.; Hursthouse, M.B.; Bala, K.; Golding, P.; Hailes, H. C. J. Am. Chem. Soc. 2006, 128, 6544. 
3. Weatherhead-Kloster, R.A.; Selby, H.D.; Miller Ш, W.B.; Mash, E.A. J. Org. Chem. 2005, 70,8693 .

4. Chumakov, Y.M.; Simonov, Y.A.; Grozav, M.; Crisan, M.; Bocelli, G.; Yakovenko, A.A.; Lyubetsky, D. Cent. Eur. J. Chem. 2006, 4, 458.

5. Wang, X.B.; Zhang, Z.T.; Wang, Q.Y. Struc. Chem. 2005, 16(5), DOI: 10.1007/s11224-0054332-5

6. Zhang, Y.; Yang, Z.; Yuan, F.; Gu, H.; Gao, P.; Xu, B. J. Am. Chem. Soc. 2004, 126, 15028.

7. Hao, M.H. J. Chem. Theory Comput. 2006, 2, 863.

8. Zuchowski, G.; Zborowski, K. Cent. Eur. J. Chem. 2006, 4, 523.

9. Bielawski, C.; Chen, Y.S.; Zhang, P.; Prest, P.J.; Moore, J.S. Chem. Commun. 1998, 1313.

10. Chen, S.; Teng, Q.; Wu, S. Cent. Eur. J. Chem. 2006, 4, 223.

11. Wang, Z.; Wu, S. Chemical Papers 2007, 61, 313.

12. Zhu, L.; Teng, Q.; Wu, S.; Xu, L.; Chen, X. Progress in Chem. 2006, 18, 707.

13. Chen, X.; Teng, Q.; Wu, S.; Xu, L. Bull. Chem. Soc. Ethiop. 2007, 21, 263.

14. Dewar, M.J.S.; Zoebisch, E.G.; Healy E.F.; Stewart, J.J.P. J. Am. Chem. Soc. 1985, 107 , 3902.

15. Thompson, M.A.; Zerner, M.C. J. Am. Chem. Soc. 1991, 113, 8210.

16. Teng, Q.; Wu, S. J. Mol. Stru.: Theochem 2005, 756, 103.

17. Wu, S.; Teng, Q. Int. J. Quantum Chem. 2006, 106, 526.

18. Frisch, M. J.; Trucks, G.W.; Schlegel, H.B.; Scuseria, G.E.; Robb, M.A.; Cheeseman, J.R.; Montgomery, J.A.; Vreven, Jr. T.; Kudin, K.N.; Burant, J.C.; Millam, J.M.; Iyengar, S.S.; Tomasi, J.; Barone, V.; Mennucci, B.; Cossi, M.; Scalmani, G.; Rega, N.; Petersson, G.A.; Nakatsuji, H.; Hada, M.; Ehara, M.; Toyota, K.; Fukuda, R.; Hasegawa, J.; Ishida, M.; Nakajima, T.; Honda, Y.; Kitao, O.; Nakai, H.; Klene, M.; Li, X.; Knox, J.E.; Hratchian, H. P.; Cross, J.B.; Adamo, C.; Jaramillo, J.; Gomperts, R.; Stratmann, R.E.; Yazyev, O.; Austin, A.J.; Cammi, R.; Pomelli, C.; Ochterski, J.W.; Ayala, P.Y.; Morokuma, K.; Voth, G.A.; Salvador, P.; Dannenberg, J.J.; Zakrzewski, V.G.; Dapprich, S.; Daniels, A.D.; Strain, M.C.; Farkas, O.; Malick, D.K.; Rabuck, A.D.; Raghavachari, K.; Foresman, J.B.; Ortiz, J.V.; Cui, Q.; Baboul, A.G.; Clifford, S.; Cioslowski, J.; Stefanov, B.B.; Liu, G.; Liashenko, A.; Piskorz, P.; Komaromi, I.; Martin, R.L.; Fox, D.J.; Keith, T.; Al-Laham, M.A.; Peng, C.Y.; Nanayakkara, A.; Challacombe, M.; Gill, P.M.W.; Johnson, B.; Chen, W.; Wong, M.W.; Gonzalez, C.; Pople, J.A. Gaussian 03, Revision B. 01, Gaussian Inc.: Pittsburgh, PA; 2003.

19. Gong, Z.; Li, X.; Li, Z. Chem. J. Chinese Universities 2004, 25, 539.

20. Fileti, E.E.; Canuto, S. Int. J. Quantum Chem. 2005, 104, 808. 